\title{
MRAC Based Speed Regulation Of An Excitation Controlled Quickresponse Induction Motor
}

Islam, S.M. Somuah, C.B. Ahmed, M.S. Abdel-Magid, Y.L.;King Fahd Univ. of Pet.Miner., Dhahran;

Industry Applications Society Annual Meeting, 1990., Conference Record of the 1990 IEEE;Publication Date: 7-12 Oct 1990;ISBN: 0-87942-553-9

King Fahd University of Petroleum \& Minerals

http://www.kfupm.edu.sa

\section{Summary}

Speed regulation of a voltage decoupled induction motor which provides optimal efficiency and quick response is discussed. A robust first-order model reference adaptive control (MRAC)-based speed controller whose stability has been proved via Lyapunov's second method is proposed. Computer simulation results for a 100-hp squirrel-cage motor show that the proposed MRAC controller has remarkably good tracking and regulation characteristics

For pre-prints please write to:abstracts@kfupm.edu.sa 